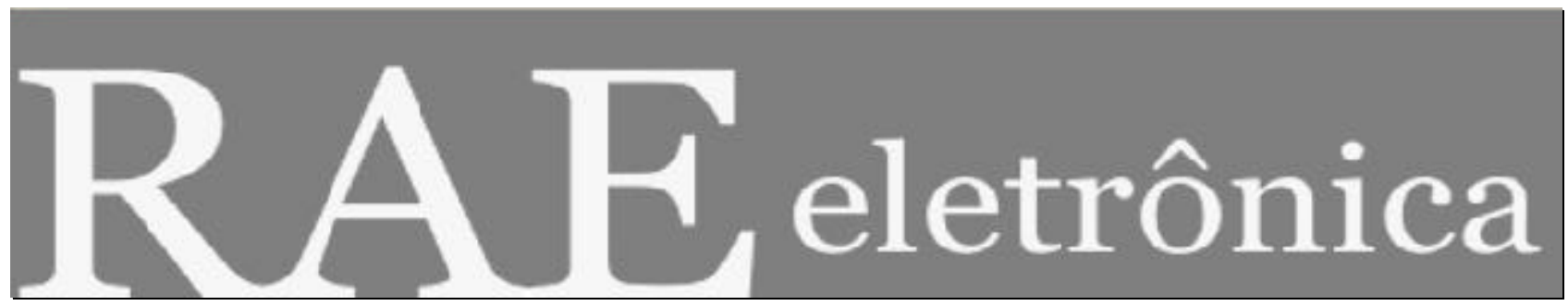

\title{
TOMADA DE DECISÃO EM FUTUROS AGROPECUÁRIOS COM MODELOS DE PREVISÃO DE SÉRIES TEMPORAIS
}

Por:

\section{Aureliano Angel Bressan}

RAE-eletrônica, v. 3, n. 1, Art. 9, jan./jun. 2004

http://www.rae.com.br/eletronica/index.cfm?FuseAction=Artigo\&ID=1914\&Secao=FINANÇAS\&Vol ume $=3 \&$ Numero $=1 \&$ Ano $=2004$

CCopyright, 2004, RAE-eletrônica. Todos os direitos, inclusive de tradução, são reservados. É permitido citar parte de artigos sem autorização prévia desde que seja identificada a fonte. A reprodução total de artigos é proibida. Os artigos só devem ser usados para uso pessoal e nãocomercial. Em caso de dúvidas, consulte a redação: redacao@ rae.com.br.

A RAE-eletrônica é a revista on- line da FGV-EAESP, totalmente aberta e criada com o objetivo de agilizar a veiculação de trabalhos inéditos. Lançada em janeiro de 2002, com perfil acadêmico, é dedicada a professores, pesquisadores e estudantes. Para mais informações consulte o site www.rae.com.br/eletronica.

RAE-eletrônica

ISSN 1676-5648

(C2004 Editora: Fundação Getulio Vargas - Escola de Administração de Empresas de São Paulo

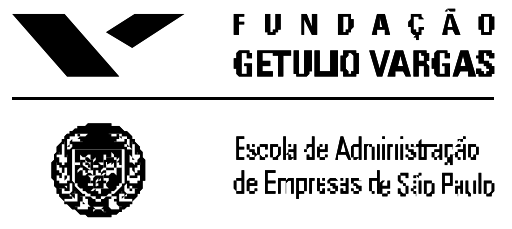




\title{
TOMADA DE DECISÃO EM FUTUROS AGROPECUÁRIOS COM MODELOS DE PREVISÃO DE SÉRIES TEMPORAIS
}

\section{RESUMO}

Este artigo trata da aplicabilidade de modelos de previsão de séries temporais como ferramenta de decisão de compra e venda de contratos futuros de boi gordo, café e soja na BM\&F, em datas próximas ao vencimento. Os modelos estudados são: ARIMA, Redes Neurais Artificiais, e Modelos Lineares Dinâmicos. Os dados correspondem às cotações semanais, nos mercados físico e futuro, entre 1996 e 1999. O objetivo consiste em calcular os retornos médios dos modelos em operações no mercado futuro de boi gordo, café e soja, de modo a indicar o potencial ou limitação dos modelos, utilizando o índice Sharpe como parâmetro de comparação. Os resultados apresentam retornos financeiros positivos na maioria dos contratos analisados, indicando o potencial de utilização desses modelos como ferramenta de decisão em negociações de contratos para datas próximas ao vencimento, com destaque para operações fundamentadas nas previsões nos MLD e ARIMA havendo, contudo, diferenças de desempenho preditivo.

\begin{abstract}
This research deals with the usefulness of times series models as a tool for buy and sell decisions of the Brazilian BM\&F future contracts, in dates nearby the expiration. The models considered were ARIMA, Artificial Neural Networks and Dynamic Linear Models. The data corresponds to the weekly quotations of coffee, soybeans and live cattle prices in the spot and futures markets, between 1996 and 1999. The main objective is to calculate the medium returns of each model in buy and sell operations, in way to provide an indication of the potentials or limitations of each one, using the Sharpe Index as a comparison tool. The results indicate the financial returns are positive in most of the analyzed contracts, indicating the potential use of those models in negotiations of contracts for dates close to expiration, with prominence for operations based in the forecasts of the ARIMA and Dynamic Linear Models.
\end{abstract}

\section{PALAVRAS-CHAVE}

Contratos Futuros Agropecuários, Tomada de Decisão, Séries Temporais.

\section{KEY-WORDS}

Agricultural Futures Contracts, Decision Making, Time Series. 


\section{INTRODUÇÃO}

Diversas técnicas de previsão auxiliam a tomada de decisões por parte dos agentes envolvidos em atividades que necessitam de planejamento, avaliação de políticas e redução da incerteza. Um dos objetivos das previsões econômicas, a redução da incerteza, é de especial importância dentro do setor agropecuário, constantemente sujeito a distúrbios irregulares.

Deste modo, a produção agropecuária necessita de instrumentos que minimizem o risco, e auxiliem no processo de tomada de decisão dos agentes participantes do agronegócio (produtores, compradores e investidores em geral). Este é o enfoque do presente estudo, que tem o objetivo básico de determinar a viabilidade de aplicação de modelos de previsão de preços na negociação de contratos futuros de boi gordo, café e soja na BM\&F.

Com o intuito de administrar riscos de mercado (oscilação de preços), o mercado futuro permite a permuta destes riscos com especuladores, apresentando-se como importante instrumento de segurança e sinalização de preços para todos os participantes da cadeia agroindustrial. HULL (1996), sintetiza essa relação, definindo os contratos futuros como compromissos de compra ou venda de um determinado ativo numa data pré-estabelecida e a um preço (cotação) que reflete as forças de oferta e demanda que atuam naquele momento.

Uma das alternativas para reduzir a incerteza no processo de tomada de decisões econômicas é a utilização de modelos de previsão de séries temporais univariadas. Baseados na análise somente da variável em si, tais modelos são construídos a partir de processos estocásticos especiais, que buscam estimar o valor futuro da variável em questão com base somente em seus valores passados. Este tipo de análise se aplica nos casos em que há um padrão persistente ou sistemático no comportamento da variável, que é possível de captar através de uma representação paramétrica (PINDYCK e RUBENFIELD, 1991).

\section{Modelos de previsão e tomada de decisão}

Uma previsão adequada deve dar suporte a uma decisão minimizadora de risco por parte dos tomadores de decisão (HARRISON e STEVENS, 1976), sendo essencial para o planejamento individual e organizacional de agentes econômicos. $\mathrm{Na}$ atividade agropecuária, a necessidade de informações preditivas de variáveis de mercado é fund amental, dada a defasagem existente entre as decisões de produção e seus efeitos (VERE e GRIFFITH, 1990).

Existem diversas formas de se obter previsões, desde métodos puramente subjetivos (opinião de especialistas) e modelos causais ou explanatórios (econométricos), até métodos extrapolativos (séries temporais) ou mesmo uma combinação destes (MAKRIDAKIS et al., 1982).

Assim, uma das possíveis alternativas para reduzir a incerteza no processo de tomada de decisões econômicas é a utilização de modelos de previsão de séries temporais ou univariados. Baseados na análise somente da variável em si, tais modelos são construídos a partir de processos estocásticos especiais, que buscam estimar o valor futuro da variável em questão com base somente em seus valores passados. 
Para GRANGER e NEWBOLD (1986), embora o conjunto de informações relativos ao comportamento de uma variável econômica qualquer não se restrinja somente ao comportamento passado da variável em si, os modelos de previsão univariados são importantes na medida em que:

a) têm aplicação imediata a baixo custo, que é relacionado ao tempo de elaboração do modelo e do erro de previsão associado ao mesmo;

b) informações externas à série em estudo são de difícil obtenção ou apresentam um custo elevado;

c) as previsões dtidas podem ser utilizadas em combinação com outras de modo a produzir uma previsão otimizada;

d) ao se produzir uma previsão univariada, tem-se a possibilidade de determinar em que medida a oscilação da variável é explicada por seu comportamento passado, dando uma idéia mais clara do padrão de comportamento da série e da necessidade de se considerar fatores externos na sua interpretação; e

e) para a maioria das séries de tempo em economia, a informação contida nas mesmas é de grande importância, embora tal fato seja desconsiderado nas abordagens mais tradicionais envolvendo previsões econômicas, que buscam na verdade estabelecer relações de causa e efeito.

Existem diversos métodos em que uma série temporal é modelada com o objetivo de extrapolar seus valores futuros. Tais métodos divergem pelo grau de complexidade de suas abordagens e pelo tratamento dado às informações contidas na série.

A análise de séries temporais se aplica nos casos em que há um padrão persistente ou sistemático no comportamento da variável, que é possível de captar através de uma representação paramétrica (PINDYCK e RUBENFIELD, 1991). Entre os modelos mais utilizados destacam-se os de suavizamento exponencial, de média móvel, modelos Box \& Jenkins, modelos Estruturais, modelos Bayesianos e de Redes Neurais.

Dois cuidados devem ser tomados na construção de modelos de previsão, de acordo com CHATFIELD (1995). A construção desses modelos assume a existência de um modelo "verdadeiro", sem considerar a incerteza quanto à sua estrutura. Deve-se ressaltar, então, que a incerteza quanto ao modelo ideal deve ser considerada na construção de um modelo de previsão, que busca captar o comportamento de uma variável econômica. Também deve ser evitado um processo comum na estatística, o data mining ("mineração de dados"), que força o ajuste de um modelo a um conjunto de dados. Feitas essas ressalvas, serão analisados os modelos a serem estimados neste trabalho.

Diversos estudos analisam a aplicabilidade destes modelos como ferramenta de apoio no processo de tomada de decisão. Neste tema, destaca-se o estudo de GRUDNITSKI e OSBURN (1993), aplicando um modelo de Redes Neurais para a previsão dos preços mensais no mercado futuro de ouro e do índice de ações S\&P 500 nos EUA, utilizando também uma estratégia de negociação com as previsões. Os resultados indicaram que as Redes Neurais foram capazes de detectar $75 \%$ e $61 \%$ das mudanças nos preços das cotações S\&P 500 e de ouro, respectivamente. Os retornos financeiros das operações também foram positivos, indicando o potencial da aplicação dessa metodologia nas operações de investimento em mercados futuros. 
Estudando o mercado futuro de boi gordo nos EUA, LEUTHOLD (1974) testou sua eficiência preditiva, analisando o comportamento relativo dos preços. Considerando que o boi gordo não é uma mercadoria estocável, o autor concluiu que as estimativas imprecisas do mercado futuro é uma característica de mercados recentemente implantados, ocorrendo até o momento em que os participantes se acostumem com os movimentos de preços e suas relações e até que se desenvolva um volume considerável de hedge.

Os resultados desse estudo foram posteriormente desenvolvidos num teste de eficiência semi-forte, conduzido por LEUTHOLD e HARTMAN (1979). O teste consiste em verificar se os preços futuros refletem toda a informação disponível publicamente, comparando seu desempenho com modelos de previsão econométricos e do tipo passeio aleatório (modelos ingênuos ou naive models). Os autores aplicaram os resultados em estratégias de negociação, verificando os possíveis retornos. Os resultados indicaram que o limite de oscilação diária, além do baixo nível de especulação, pode comprometer a validade dos mercados futuros como instituições fornecedoras de previsões e meio de formação racional de preços.

A eficiência preditiva dos mercados futuros de boi gordo nos EUA também foi estudada por GARCIA et al. (1988). Esses autores confrontaram seus resultados com previsões dos modelos ARIMA e modelos econométricos tradicionais, para séries de preço mensais entre 1976 e 1981. Os resultados indicaram que ao menos um dos modelos é superior às cotações do mercado futuro em termos de erro quadrado médio. Os autores definem ainda uma condição suficiente para que se verifique que os ganhos com o uso de modelos seja ma ior que o custo de construção e aplicação dos mesmos, que consiste na aplicação destes em estratégias de compra/venda de contratos. Os retornos da estratégia dariam, então, uma medida direta do benefício dos modelos. As simulações de mercado realizadas com as previsões desses modelos geraram retornos com alto risco associado, levando os autores a concluir que não existiriam fortes evidências de ineficiência nesse mercado.

Ao compararem a precisão de previsões comerciais de preços para trigo, soja, algodão, boi gordo e suínos, frente a previsões no mercado futuro nos EUA, JUST e RAUSSER (1981) obtiveram resultados divergentes entre empresas que atuam no mercado futuro de commodities. Em geral, porém, os preços futuros apresentaram um desempenho superior na mé dia, ressaltando então o importante papel dos mercados futuros como instrumentos de gerenciamento de risco.

O estudo de KENYON et al. (1993) testou a capacidade preditiva dos preços futuros nos mercados de milho e soja nos EUA, através de uma análise de regressão da variância das previsões dos preços antes e depois de 1973. Os resultados indicaram um declínio na precisão preditiva associado a erros na previsão de safra e à queda da influência do crédito rural na determinação do preço dos produtos.

Portanto, o papel dos preços futuros como sinalizadores dos preços no mercado físico parece ser uma preocupação constante entre estudiosos da área de mercados futuros agrícolas. De modo geral, os resultados indicam que os preços futuros podem refletir um amplo conjunto de informações, mas fornecem previsões pouco acuradas dos preços no mercado físico. Previsões baseadas em modelos quantitativos (econométricos e de séries temporais) também não fornecem resultados satisfatórios nas previsões do mercado físico, conforme análise crítica de TOMEK (1997).

TAYLOR (1988) estudou a aplicabilidade de uma regra de negociação em mercados futuros de $T$ Bonds dos EUA. As previsões para a tomada de decisão são baseadas em interpretações de tendência de mercado e previsões de modelos ARIMA. Os retornos são calculados usando os preços de fechamento para um mesmo contrato. Os resultados apontaram para retornos positivos da estratégia de 
negociação, indicando assim uma relativa ineficiência do mercado futuro de $T$-Bonds norte-americano em se adaptar instantaneamente à chegada de novas informações.

Através da análise técnica, SILVA (1996) estudou a viabibilidade de um modelo de maximização de ganhos em diversos contratos futuros no Brasil avaliando os riscos de compra e venda de contratos no momento certo. Seus resultados indicam a necessidade de se estabelecer uma faixa de preços (diária, semanal ou mensal) em que o ativo deve oscilar antes de iniciar cada pregão, além de ser fundamental determinar com precisão o fim de uma tendência e o conseqüente início da tendência inversa.

Por fim, utilizando dados semanais, NTUNGO e BOYD (1998) estudaram o desempenho de modelos ARIMA e de Redes Neurais em estratégias de negociação nos mercados futuros de milho, prata e marco alemão. Os resultados são equivalentes em termos de retornos financeiros para os dois modelos, com resultados positivos nos mercados de milho e prata.

Entretanto, os resultados apresentados pelos diversos autores não são definitivos, no sentido de que existe um vasto campo de estudo acerca da comparação do desempenho preditivo de modelos de previsão. Um aspecto que é pouco explorado nestes estudos é a aplicação dessas previsões por agentes econômicos, com o intuito de avaliar ganhos ou perdas e o risco associado com decisões baseadas nestes modelos. Esta constatação colabora na determinação do problema de pesquisa a ser estudado.

\section{DEFINIÇÃO DO PROBLEMA E OBJETIVOS}

Nas transações envolvendo produtos agrícolas, a administração do risco relativo à volatilidade dos preços é um componente fundamental. Deste modo, a formação de previsões consistentes torna-se um importante instrumento na tomada de decisão dos participantes do mercado.

Portanto, o objetivo deste estudo consiste em construir previsões das cotações do mercado físico, sinalizando posições de compra e venda no mercado futuro. Com isso, pretende-se comparar os retornos médios de cada modelo em operações de compra e venda nos mercado futuro das commodities consideradas, de modo a analisar o potencial destes instrumentos como ferramentas de suporte ao processo de tomada de decisão de agentes ligados mercado futuro de boi gordo, café e soja na BM\&F.

\section{METODOLOGIA}

A metodologia utilizada fundamenta-se na construção de modelos univariados de previsão de preços com base em dados de séries temporais. Há uma grande variedade de modelos aplicáveis a estudos desta natureza. Para fins desta pesquisa, optou-se por selecionar os modelos ARIMA, de Redes Neurais Artificiais e Modelos Lineares Dinâmicos. A seguir, é feita uma breve apresentação dos procedimentos estatísticos para a construção destes modelos.

\section{Modelos ARIMA}

Os Modelos ARIMA (Auto-regressivo - Integrado - Média móvel), inicialmente formulados por BOX e JENKINS (1976), baseiam-se na idéia de que uma série temporal não-estacionária pode ser modelada a partir de $d$ diferenciações e da inclusão de um componente auto-regressivo e um componente média móvel.

A maioria das séries econômicas são não-estacionárias, no sentido de que a média e a variância não são constantes ao longo da amostra (GRANGER e NEWBOLD, 1986). No entanto, tais séries podem, ser 
transformadas em séries estacionárias por diferenciação ou seja, trabalhando com a diferença da série de $t$ para $t-1$.

Séries não-estacionárias, em que as observações são descritas por tendências estocásticas, são conhecidas como séries não-estacionárias homogêneas (ABRAHAM e LEDOLTER, 1983). Tomando sucessivas diferenças $\nabla y_{t}, \nabla^{2} y_{t}, \ldots$, a série não-estacionária homogênea $y_{t}$ pode ser convertida em uma série estacionária $z_{t}$ :

$$
z_{t}=\nabla^{d} y_{t}=(1-B)^{d} y_{t}
$$

sendo $z_{t}$ um processo estacionário, ele pode ser descrito através de uma modelagem ARMA $\varphi, q$ ), da seguinte forma:

$$
\phi_{p}(B) z_{t}=\theta_{0}+\theta_{q}(B) a_{t}
$$

que, ao se considerar a diferenciação $(d)$ de $y_{t}$, corresponderá a um $\operatorname{Modelo} \operatorname{ARIMA}(p, d, q)$, com

$$
\phi_{p}(B)(1-B)^{d} y_{t}=\theta_{0}+\theta_{q}(B) a_{t}
$$

em que o primeiro termo de (3) é o operador auto-regressivo $\operatorname{AR}(p)$, ao passo que o segundo termo representa o operador média móvel $\operatorname{MA}(q)$, sendo $a_{\mathrm{t}}$ é um processo ruído branco. Se $\theta_{0}$ for diferente de zero, a série integrada apresentará tendência determinística, ou seja, a série apresenta tendência crescente ou decrescente, que é independente dos distúrbios aleatórios (PINDYCK e RUBENFIELD, 1991).

De acordo com BOX e JENKINS (1976), a modelagem ARIMA deve seguir três passos básicos antes de se proceder aos cálculos das previsões para a variável $y_{t}$ : a) identificação/seleção do modelo, b) estimação e c) verificação. O passo mais importante é o primeiro, em que se determinam os valores apropriados de $p, d$ e $q$.

Com relação à série diferenciada (e portanto estacionária) $z_{t}$, pode-se reescrever a equação (2) como

$$
a_{t}=\theta_{1} a_{t-1}+\ldots+\theta_{q} a_{t-q}+z_{t}-\phi_{1} z_{t-1}-\ldots-\phi_{p} z_{t-p}
$$

dado o pressuposto de que $a_{\mathrm{t}}$ é independente e representado por uma distribuição normal com média zero e variância $\sigma^{2}$. A equação (4) descreve o modelo ARIMA $(p, d, q)$ na sua forma generalizada, para construção de previsões de séries estacionárias.

O processo de estimação é complexo, requerendo um método iterativo de cálculo. Inicialmente, deve-se identificar os componentes do modelo, através de testes de raiz unitária e análise do correlograma, de modo a conduzir a estimação. Obtida a estimação, procede-se com a verificação do modelo. Esta é realizada analisando-se o comportamento dos resíduos. Especificamente, deve-se verificar se os resíduos $\hat{a}_{t}$ seguem um processo tipo ruído branco, ou seja, com média próxima de zero, variância constante e correlações não significativas ABRAHAM e LEDOLTER(1983).

Com a conclusão dos três passos básicos (identificação, estimação e verificação), é possível calcular previsões para os valores futuros de $y_{t}$. O modelo (4) é então, conforme ABRAHAM e LEDOLTER 
(1983), representado em um formato equivalente, considerando a série original $y_{t}$ :

$$
y_{t}=\pi_{1} y_{t-1}+\pi_{2} y_{t-2}+\ldots+a_{t}
$$

sendo os pesos $\pi$ dados por

$$
1-\pi_{1} B-\pi_{2} B^{2}-\ldots=\frac{\phi_{p}(B)(1-B)^{d}}{\theta_{q}(B)}
$$

O objetivo dessa estimação consiste em prever $y_{T+l}(l \geq 1)$ como resultado de uma combinação linear das observações $y_{T}, y_{T-1}, \ldots$. Consideraram-se, então, previsões do tipo

$$
y_{T}(l)=\eta_{0} y_{T}+\eta_{1} y_{T-1}+\eta_{2} y_{T-2}+\ldots
$$

que podem também serem representadas por uma combinação linear dos distúrbios passados:

$$
y_{T}(l)=\xi_{0} a_{T}+\xi_{1} a_{T-1}+\xi_{2} a_{T-2}+\ldots
$$

A atualização da previsão é uma combinação linear da previsão anterior de $y^{T+1+1}$ feita no instante $\mathrm{T}$ com o erro de previsão um passo à frente mais recente, representado por

$$
e(1)=y_{T+1}-y_{T}(1)=a_{T+1}
$$

Segundo GRANGER e NEWBOLD (1986), a metodologia Box \& Jenkins deve ser aplicada em séries com mais de 50 observações, em casos onde as características estruturais são desconhecidas. FISCHER (1982) ressalta outro importante aspecto dos modelos ARIMA, relacionado ao limite do horizonte de previsão. Segundo o autor, os ARIMA apresentam a característica geral de suas previsões reverterem à média quando o horizonte de previsão aumenta. Nesse sentido, o potencial de previsão destes modelos está limitado a horizontes de curto prazo.

\section{Modelos Lineares Dinâmicos}

Em contraposição à abordagem estática dos modelos ARIMA, os modelos Lineares Dinâmicos ou Estruturais são formulados com a característica de incorporar mudanças nos parâmetros à medida que ocorrem evoluções na série temporal estudada. O aumento no número de observações da série é interpretado, então, como informação adicional ao conjunto de informações atuais, fazendo com que os parâmetros apresentem uma evolução dinâmica, impedindo qualquer quantificação estática das relações subjacentes ao comportamento global da série (POLE et. al., 1994).

Em tais modelos, a série yt é decomposta em termos da tendência $\left(\mu_{t}\right)$, do ciclo $\left(\psi_{t}\right)$, da sazonalidade $\left(\gamma_{t}\right)$ e de um componente irregular $\left(\varepsilon_{t}\right)$ :

$$
y_{t}=\mu_{t}+\gamma_{t}+\psi_{t}+\varepsilon_{t}
$$

A especificação de cada um dos componentes dá o modelo completo. A equação (10) também é conhecida como equação das medidas ou equação das observações. Existem diversas variantes dessa equação básica, que divergem da mesma pela ausência de um dos componentes ou pela relação dos mesmos (que pode ser multiplicativa), em função da natureza dos dados analisados. 


\section{FINANÇAS - TOMADA DE DECISÃO EM FUTUROS AGROPECUÁRIOS COM MODELOS DE PREVISÃO DE SÉRIES TEMPORAIS \\ Aureliano Angel Bressan}

A operacionalização do modelo é obtida adotando-se o modelo de espaço de estados e utilizando-se o filtro de Kalman para a atualização sequencial dos componentes não observáveis.

A representação em espaço de estados é feita através de um sistema de duas equações dinâmicas que descrevem a maneira pela qual as observações são geradas em função do vetor de estados e a evolução dinâmica desse vetor.

Assim, a abordagem de espaço de estados serve para reformular o modelo, atualizando-o para novas observações da série $\mathrm{y}_{t}$. $\mathrm{O}$ filtro de Kalman é então utilizado para criar uma estimativa ótima do estado, buscando estimativas dos componentes através de um algoritmo específico. O filtro de Kalman consiste basicamente de um algoritmo que fornece estimativas atualizadas do vetor de estados a cada instante de tempo.

SOUZA (1989) descreve o modelo de espaço de estados a partir de um modelo linear dinâmico (MLD) da forma:

$$
\begin{aligned}
& Y_{t}=\underline{F}_{t}{ }^{\prime} \underline{\theta}_{t}+v_{t} \\
& \underline{\theta}_{t}=\underline{G}_{t} \underline{\theta}_{t-1}+\underline{\omega}_{t}
\end{aligned}
$$

em que

$Y_{t}$ é o processo representando a observação do sistema no instante $t$;

$\underline{F}_{t}$ é um vetor $m \times 1$ conhecido para todo $t=1,2, \ldots, m$;

$\underline{\theta}_{t}$ é o vetor $m \times 1$ representando o estado do sistema em $t$ (vetor de estado);

$\underline{G}_{t}$ é uma matriz $m \times m$ conhecida para todo $t=1,2, \ldots, m$;

$v_{t}$ é a perturbação associada às observações, seguindo um processo ruído branco gaussiano com variância $V_{t}$; e

$\underline{\omega}_{t}$ é um vetor $m \times 1$ da perturbação associada ao estado, também um processo ruído branco gaussiano vetorial com matriz de covariância $W_{t} m \times m$.

Assume-se ainda que $\mathrm{E}\left[v_{t}, \underline{\omega}_{t-k}\right]=0$ para todo $k=0,1,2, \ldots$.

A equação (11) descreve a forma pela qual as observações do processo são geradas em função do vetor de estado e é correspondente à equação das medidas ou das observações (10). A equação (12) representa a evolução dinâmica do vetor de estado não observado e é conhecida como equação do sistema ou de transição.

A construção dos Modelos Estruturais seguem os passos propostos por SOUZA (1989) com o diferencial de, inicialmente, logaritimizar a série e de se modelar apenas a tendência, de acordo com ANDREWS (1994). A análise é feita com intervenções, quando o modelo indicar um ajustamento pobre em determinado período. 


\section{Modelos de Redes Neurais}

Aureliano Angel Bressan

Os Modelos de Redes Neurais Artificiais (RNA) se diferenciam dos modelos tradicionais de previsão por serem modelos não-paramétricos, envolvendo algoritmos de aprendizado. Tais algoritmos buscam imitar a estrutura de interconexões do cérebro humano, com o intuito de incorporar o padrão de comportamento de uma série temporal de modo a prever, da maneira mais eficiente possível, valores futuros dessa série (TURBAN, 1993).

Tais modelos podem ser interpretados como uma classe de modelos de regressão não-linear, que permite o analista ajustar grande número de parâmetros e testar diferentes configurações para um ajuste (CHATFIELD, 1996). Essas diferentes configurações podem ser interpretadas como formas funcionais alternativas para um ajuste adequado da rede em termos do número de camadas da rede e do número de neurônios em cada camada (FERNANDES et al., 1995).

A construção de um Modelo RNA envolve desde a modelagem adequada da rede até as transformações utilizadas para transmitir os dados a ela e aos métodos utilizados para interpretar os resultados obtidos. Esses três aspectos (modelagem, transformações e interpretação) são fundamentais na utilização das RNA para previsão de preços.

De acordo com ZIRILLI (1996), as RNA são constituídas de número significativo de neurônios artificiais (ou elementos processadores) unidos por um grande número de conexões ponderadas que codificam o conhecimento da rede. Muitos neurônios podem processar sua informação, independentemente dos outros, embora existam ligações e dependências básicas na maioria desses neurônios (TURBAN, 1993).

A ênfase das RNA reside no aprendizado automático das representações internas ou ponderações, através de dois métodos de treinamento (algoritmos): supervisionado e não-supervisionado. No algoritmo supervisionado, a solução ótima desejada deve ser especificada a priori, com o processo de aprendizado montado a partir de valores aleatórios para as ponderações, modificando-as iterativamente até a obtenção da solução ótima. $\mathrm{O}$ algoritmo não-supervisionado não requer a especificação da solução ótima, permitindo que os neurônios determinem quais as ponderações características da série, de modo a determinar o padrão de comportamento desta (ZIRILLI, 1996).

A unidade básica de uma RNA é o neurônio artificial (Figura 1). Sua estrutura busca reproduzir a estrutura do neurônio humano, tendo, assim, três componentes básicos: um elemento somatório $\Sigma$, uma função de ativação $f$ e as ponderações $w_{i}$.

\section{Figura 1 - O neurônio artificial}

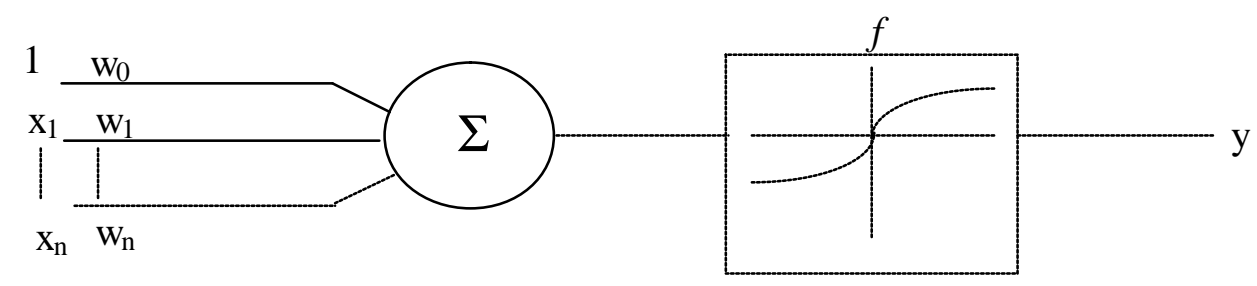

Fonte: ZIRILLI (1996) 
O neurônio artificial soma os $x_{n}$ entradas/insumos ponderados por $w_{i}$, que passa pela função de ativação $f$, resultando no produto $y$. Matematicamente, esse procedimento equivale a

$$
y=f\left(\sum_{i=0}^{N} x_{i} w_{i}\right)
$$

Na modelagem das RNA, a forma típica da função de ativação é a seguinte, segundo CORRÊA e PORTUGAL (1998):

$$
f=\frac{1}{1+e^{-z}}
$$

em que

$$
z=\sum_{i=0}^{N} x_{i} w_{i}
$$

Como pode ser observado na equação 70 , o somatório vai de 0 a $\mathrm{N}$. Isso porque $x_{0}$ constitui o viés e assume o valor 1, conforme ilustrado na Figura 2. O viés é adicionado para dar capacidade do neurônio em tender para um nível específico. A RNA é, então, constituída de diferentes camadas, conforme PORTUGAL (1995) e KOHZADI et al. (1995) (Figura 2).

\section{Figura 2 - RNA do Tipo Feedforward}

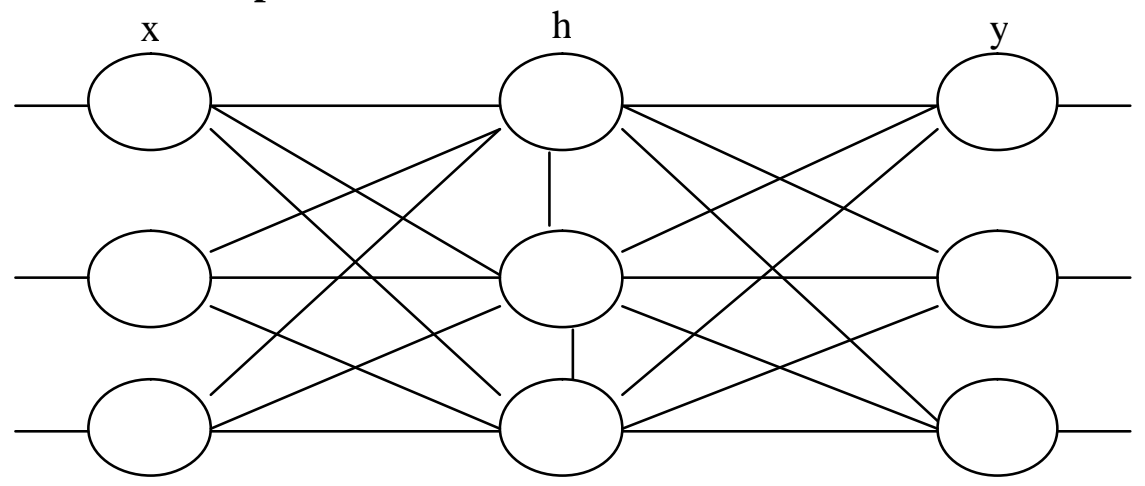

Fonte: KOHZADI et al. (1995)

A camada de entrada (x) fornece os insumos (dados ou informações) sem nenhum procedimento computacional. A camada oculta $(h)$ recebe as informações da camada de insumos, ou de outra camada oculta, e fornece informações para outra camada oculta ou para a camada de saída. A camada de saída (y) recebe informações da camada oculta e fornece o produto da rede. A rede descrita na Figura 2 é do tipo feed forward (transmissão em um só sentido), um exemplo simplificado de RNA, posto que as informações podem, na verdade, movimentar-se em várias direções.

O algoritmo mais estudado e bem-sucedido no processo de aprendizagem de uma RNA é o algoritmo de backpropagation, que tem apresentado os melhores resultados em diversos estudos 


\section{FINANÇAS - TOMADA DE DECISÃO EM FUTUROS AGROPECUÁRIOS COM MODELOS DE PREVISÃO \\ DE SÉRIES TEMPORAIS \\ Aureliano Angel Bressan}

(FITZPATRICK, 1999). Esse algoritmo permite realizar as transformações necessárias à transmissão dos dados para a rede, possibilitando a formação de previsões consistentes com o comportamento da série em estudo.

Para aprendizado, a amostra é dividida em duas faixas. Na primeira, denominada faixa-treino, a rede capta o padrão de comportamento da série para, na faixa-teste, testar se o erro é minimizado. A faixatreino deve ser suficientemente grande para captar o padrão de comportamento da série, e a faixa-teste deve ser representativa das condições futuras que a rede vai tentar captar para realização da previsão (FITZPATRICK, 1999).

O algoritmo de backpropagation ajusta, então, as ponderações de modo a minimizar os erros de previsão dentro da faixa-teste. Baseado nesse erro entre observado e estimado, os pesos são ajustados de modo a obter um erro mínimo. O algoritmo de backpropagation é formalizado nas seguintes equações, de acordo com CORRÊA e PORTUGAL (1998) e PORTUGAL (1995):

$$
\begin{aligned}
& \Delta w_{i j, k}^{n}=\eta \cdot \delta_{j, k} \cdot y_{i, k-1} \\
& w_{i j, k}^{n+1}=w_{i j, k}^{n}+\Delta w_{i j, k}^{n} \\
& \delta_{j, k}=\left(\frac{d y}{d z}\right)_{i, k} \cdot\left(y_{i, k}-y_{i, k}^{T}\right)
\end{aligned}
$$

com $i=1,2, \ldots, I ; j=1,2, \ldots, J$ e $k=K$

em que

$\eta=$ coeficiente de aprendizado $(0,01 \leq \eta \leq 1,00)$

$y_{i, k}=$ saída do neurônio $i$ na camada $k$;

$y_{i, k}^{T}=$ valor desejado para $y_{i, k} ; \mathrm{e}$

$w_{i j, k}^{n}=$ ponderação ligando o neurônio $i$ na camada $k-1$ ao neurônio $j$ na camada $k$ no passo $n$.

O algoritmo só pode ser aplicado à camada de saída, pois se pressupõe que o valor desejado de saída seja conhecido, o que é possível na última camada, em que $k=K$. Nas camadas ocultas, o valor de $\delta_{i, k}$ é dado por uma propagação para trás de $\delta_{i, k}$, a partir das ponderações em cada camada, com

$$
\delta_{j, k}=\left(\frac{d y}{d z}\right)_{i, k}\left(\sum_{j} \delta_{j, k} w_{i j, k}\right) ; \quad k=1,2, \ldots, K-1 .
$$

A convergência ao mínimo pode ser obtida a partir das equações (16) e (17), através de uma transformação auto-regressiva, levando a, de acordo com CORRÊA e PORTUGAL (1998),

$$
\Delta w_{i j, k}^{n+1}=\eta\left(\delta j, k \cdot y_{i, k-1}\right)+\alpha\left(\Delta w_{i j, k}^{n}\right)
$$




\section{FINANÇAS - TOMADA DE DECISÃO EM FUTUROS AGROPECUÁRIOS COM MODELOS DE PREVISÃO DE SÉRIES TEMPORAIS$$
w_{i j, k}^{n+1}=w_{i j, k}^{n}+\Delta w_{i j, k}^{n+1}
$$

Definido o algoritmo, a RNA pode identificar o padrão da série de preços nos indicadores de preço, bem como realizar previsões a partir de generalizações da série num espaço N-dimensional (Figura 3).

\section{Figura 3 - Esquema de uma RNA para previsão de preços}

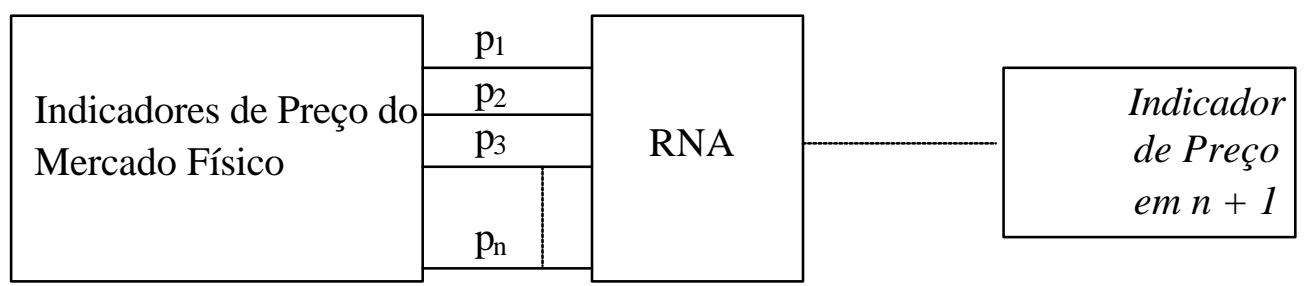

Fonte: ZIRILLI (1996)

Esse esquema simplificado ilustra o procedimento necessário na modelagem de uma RNA aplicada à previsão de preços no mercado físico. Contudo, a escolha da estrutura ideal da RNA é uma tarefa difícil, envolvendo desde a definição do número de observações a ser utilizado até a determinação dos componentes da camada oculta. Segundo KOHZADI et al. (1995), o número inicial de neurônios na camada de entrada pode ser estabelecido pela natureza do problema estudado e pelo seu referencial teórico.

PORTUGAL e FERNANDES (1996) traçaram um paralelo entre os Modelos RNA e os Modelos Econométricos tradicionais. Enquanto os Modelos Econométricos estimam parâmetros para explicar o comportamento de uma variável endógena a partir de variáveis exógenas, os Modelos RNA produzem um padrão de comportamento (variável endógena) a partir das informações obtidas nos dados (variáveis exógenas) e das ponderações (similares aos parâmetros do modelo econométrico tradicional).

Há de se ressaltar uma diferença básica entre esses modelos relacionada com a camada oculta, que introduz uma relação não- linear entre as entradas $x_{0}$ e o produto $y$. Além disso, os Modelos RNA não contam com uma base estatística predeterminada, ou seja, não trabalham com variáveis aleatórias que possuem determinada distribuição de probabilidade, apenas com entradas e saídas de informações.

A ausência de uma base estatística impede, nesse sentido, a construção de intervalos de confiança para previsões resultantes dos Modelos RNA. Conseqüentemente, as previsões são sempre pontuais, mas passíveis de comparação com outros modelos, através de medidas como o Erro Percentual Médio de Previsão.

De acordo com FARAWAY e CHATFIELD (1995), a obtenção de boas previsões com uma rede neural depende: a) do tipo de dados, b) da técnica do analista na escolha do modelo apropriado e c) dos métodos numéricos usados para ajustar o modelo e calcular as previsões. Esses autores destacaram a utilidade de estudos de caso, com competição entre séries e modelos, para contornar essas limitações.

Conforme destacou CHATFIELD (1996), a obtenção de um bom ajuste da rede não é garantia de previsões acuradas, o que se deve à incerteza quanto à arquitetura ideal da rede. Essa limitação é ressaltada na literatura como a dificuldade de se determinar a arquitetura ótima da rede, dada a inexistência de um critério universalmente aceito de escolha. Tal problema reflete na incerteza quanto à 
determinação do tamanho da rede, em termos do número de entradas e do tamanho da camada oculta.

\section{Critérios Para Avaliação do Desempenho Operacional dos Modelos}

Os modelos univariados são construídos de modo a captar o comportamento dos preços ao longo do período analisado, para o cálculo de previsões ex-post um passo à frente. Os modelos são reestimados para cada contrato analisado, de modo a se proceder à incorporação de novas informações sobre o comportamento dos preços no tempo, de modo a fornecer previsões mais precisas para a semana em que se realiza a negociação do contrato.

O desempenho de cada modelo nos diferentes mercados é avaliado a partir de um critério que consiste em aplicar as previsões dos modelos em simulações da operação de compra e venda de contratos futuros, conforme definido em GARCIA et al. (1988). O processo de simulação com as previsões dos modelos é construído de modo que são tomadas posições compradas no mercado futuro se o valor previsto excede o preço futuro, e vendem-se contratos futuros se a previsão é abaixo da cotação da $\mathrm{BM} \& \mathrm{~F}$, seguindo as regras de comercialização e considerando os custos de realização das operações.

Por si, o retorno financeiro é uma medida sem muito valor para julgar o desempenho de um sistema de negociação. A medida adequada para a comparação entre sistemas de negociação deve considerar a relação retorno-risco dos modelos.

Pode-se utilizar então uma medida clássica de retorno-risco, o Índice Sharpe (IS), que é definido na sua forma reduzida por SCHWAGER (1984), como sendo:

$$
I S=\frac{R}{\sigma_{R}}
$$

onde R é a média dos retornos do sistema de negociação, e $\sigma_{\mathrm{R}}$ é o desvio padrão dos retornos.

A premissa básica do IS é de que o desvio padrão é uma medida de risco. Ou seja, quanto maior o desvio padrão, maior o risco do sistema de negociação. Se o desvio padrão é baixo, é razoável assumir que o retorno atual estará perto do retorno esperado. Por outro lado, se o desvio padrão é alto, isto sugere que há uma alta probabilidade de que o retorno atual deve variar significativamente. Quanto maior o IS, melhor é o desempenho do modelo nas operações de compra/venda de contratos.

É importante observar que o IS utilize dados passados para prever o desempenho futuro de investimentos, com base na premissa de que agentes participantes do mercado buscam maiores índices de modo a otimizar o desempenho preditivo de suas estratégias. Todavia, HAUGEN (1997) destaca algumas limitações da utilização do índice como medida de avaliação, ligadas principalmente ao fato de que o índice pode gerar medidas viesadas de desempenho, dado o desconhecimento da estrutura de formação dos preços spot e futuros. Ademais, o índice utiliza informações ex-post para prever o comportamento futuro da estratégia de negociação de ativos, utilizando a premissa de que os retornos passados, bem como o desvio-padrão, resumem o risco previsto dos ativos e das estratégias sob avaliação.

Entretanto, para fins de avaliação do desempenho dos modelos propostos neste estudo, o índice de Sharpe é uma medida adequada de avaliação, visto que gera uma mesma base de comparação do desempenho simulado dos modelos nos três mercados analisados, em termos da relação risco-retorno 
observada.

\section{FONTE DE DADOS}

A comparação dos três modelos será feita a partir de uma base de dados secundária proveniente da Bolsa de Mercadorias e Futuros (BM\&F). Tal base corresponde ao indicador de preço Esalq/BM\&F para toda quarta-feira útil entre 09 de setembro de 1996 e 31 de dezembro de 1999 para os contratos futuros de boi gordo, café e soja. As previsões são construídas a partir da penúltima semana do mês de janeiro de 1998, e atualizadas seqüencialmente nos meses seguintes, de modo a proceder com a previsão para os contratos no biênio 1998/99.

\section{ANÁLISE E DISCUSSÃO DOS RESULTADOS}

Para a verificação dos resultados, são analisados meses em que existem contratos futuros negociados entre 1998 e 1999. Assim, a análise concentra-se nos retornos financeiros da aplicação das previsões obtidas de cada modelo, obtidas a partir de previsões um-passo-à-frente, correspondentes à semana anterior ao vencimento de cada contrato.

São incluídos os custos operacionais da BM\&F, a saber: a Taxa Operacional Básica (TOB) que corresponde a $0,3 \%$ do valor do preço de ajuste do dia anterior e é pago à corretora, e a Taxa da Bolsa (emolumentos), correspondente a 6,32\% da TOB. Não se considera a inclusão da Margem de Garantia, pois as operações são encerradas por diferença.

Para os três mercados analisados, os modelos apresentam desempenho distinto, ao sinalizar diferentes estratégias em termos de compra/venda de contratos, como pode ser observado nos Quadros 1 a 3.

\section{Quadro 1 - Estatísticas e Índice Sharpe dos Retornos Financeiros} das simulações: contratos de boi gordo da BM\&F (1998/1999).

\begin{tabular}{lccc}
\hline & ARIMA & RNA & MLD \\
\hline Média (US\$) & 936,56 & 892,56 & $\mathbf{1 . 0 1 5 , 5 2}$ \\
Desvio Padrão (US\$) & $2.331,45$ & $2.349,40$ & $\mathbf{2 . 2 9 6 , 6 9}$ \\
Índice Sharpe & 0,402 & 0,380 & $\mathbf{0 , 4 4 2}$ \\
& & & \\
\hline
\end{tabular}

Fonte: Resultados da pesquisa.

Quadro 2 - Estatísticas e Índice Sharpe dos Retornos Financeiros das simulações: contratos de café da BM\&F (1998/1999).

\begin{tabular}{llll}
\hline & \multicolumn{1}{c}{ ARIMA } & \multicolumn{1}{c}{ RNA } & \multicolumn{1}{c}{ MLD } \\
\hline \multicolumn{1}{c}{ Média (US\$) } & $\mathbf{1 . 3 8 0 , 5 9}$ & $-351,41$ & $\mathbf{1 . 3 8 0 , 5 9}$ \\
Desvio Padrão (US\$) & $\mathbf{8 . 7 5 3 , 0 6}$ & 8865,81 & $\mathbf{8 . 7 5 3 , 0 6}$ \\
Índice Sharpe & $\mathbf{0 , 1 5 8}$ & $-0,040$ & $\mathbf{0 , 1 5 8}$ \\
\hline
\end{tabular}

Fonte: Resultados da pesquisa. 


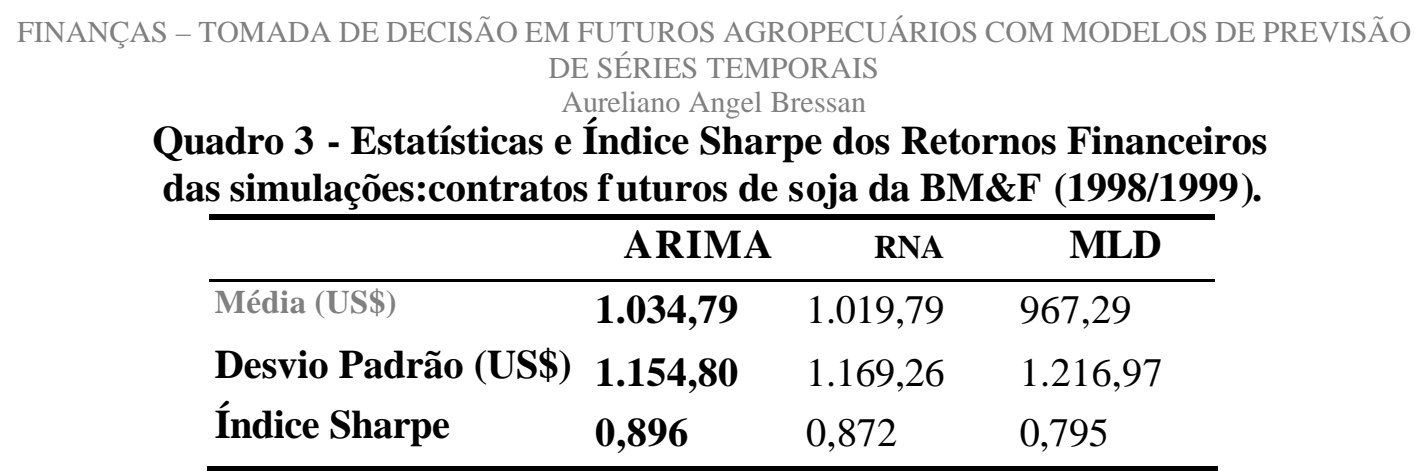

Fonte: Resultados da pesquisa.

Em relação ao contrato futuro de boi gordo, todos os modelos apresentam valores positivos do Índices Sharpe, indicando o potencial dos mesmos em aplicações no mercado futuro de boi gordo. Os altos valores dos desvios-padrão nos modelos são decorrentes da alta volatilidade dos preços da arroba do boi gordo entre fevereiro e dezembro de 1999, determinando assim uma variabilidade significativa nos retornos verificados em cada contrato negociado.

Os modelos ARIMA e Lineares Dinâmicos apresentam as mesmas médias de retorno nas negociações dos contratos futuros de café. Isto decorre do fato de sinalizarem estratégias idênticas de tomada de posição no mercado futuro, de venda de contratos, para posterior recompra, ao longo do período analisado. A alta volatilidade nos retornos observados para os três modelos decorre, como no caso do mercado de boi gordo, da alta volatilidade dos preços. Todavia, no mercado de café, essa volatilidade afeta de modo especial os contratos de maio e julho de 1998, e julho e setembro de 1999, períodos em que o mercado físico se caracterizou por uma significativa volatilidade nas cotações, em função da variabilidade dos preços no mercado internacional. Esta alta volatilidade compromete os retornos gerados pelas previsões do modelo de Redes Neurais Artificiais, que não captam as reversões de tendência de modo eficiente.

Nas negociações envolvendo contratos futuros de soja, os modelos ARIMA e de Redes Neurais apresentam as maiores médias de retornos financeiros. Já os valores obtidos para os índices Sharpe nos três modelos de previsão sinalizam para um potencial da aplicabilidade destes modelos no mercado futuro de soja, mas também apontam para o risco de sua aplicação. Isto porque o retorno médio ainda é menor que o risco associado à operacionalização dos modelos no mercado, uma vez que o valor do indicador é inferior a 1 . O valor positivo do índice sinaliza para ganhos líquidos ao longo do período, para todos os modelos analisados.

A diferença no desempenho financeiro dos modelos está centrada na capacidade de identificar de modo preciso as tendências de mercado nas datas próximas ao vencimento dos contratos. Tal habilidade deve ser capaz de proporcionar ganhos significativos em comparação com modelos que não conseguem captar as mesmas no momento certo.

A análise agregada das simulações de compra e venda de contratos de boi gordo aponta para um melhor desempenho dos modelos ARIMA, além dos Modelos Lineares Dinâmicos, ambos com boas médias de retorno financeiro.

É possível ainda generalizar os resultados em termos do grau de liquidez dos mercados estudados. Nos mercados com maior média de volume de negociação de contratos, como boi gordo e café, os modelos ARIMA e Lineares Dinâmicos fornecem resultados satisfatórios, com maior peso para retornos positivos. Porém, tais retornos apresentam alta variabilidade, com um expressivos graus de dispersão, em especial no mercado de café. 
A menor liquidez é observada no mercado futuro de soja. Porém, é neste mesmo mercado que se observam os maiores valores do Índice Sharpe para os modelos analisados. Tal resultado sinaliza para o potencial de aplicação destes modelos em operações de compra e venda de contratos em mercados com baixa liquidez, tal como a verificada para a soja.

Pode-se inferir então, com base nos resultados obtidos para o período de 1998 e 1999, que os modelos ARIMA são os mais adequados para a sinalização de tendências de mercado com vistas à operação de compra e venda de contratos futuros. O mesmo pode ser afirmado com relação aos Modelos Lineares Dinâmicos que também sinalizam corretamente as tendências de mercado, produzindo retornos satisfatórios nas operações de compra e venda para os agentes que atuam nos mercados futuros de boi gordo, café e soja.

\section{CONCLUSÕES}

O presente estudo foi elaborado com o objetivo de testar a aplicabilidade de modelos de previsão de séries temporais em negociações de contratos futuros de boi gordo, café e soja, em operações de compra e venda de contratos nesses mercados. Os modelos estudados foram os ARIMA, Estruturais (Lineares Dinâmicos) e de Redes Neurais.

A construção dos modelos se baseou em dados secundários obtidos junto à Bolsa de Mercadorias e Futuros (BM\&F), para a realização de previsões entre janeiro de 1998 e dezembro de 1999, nos meses em que se negociaram contratos de cada produto. Os resultados são analisados a partir do desempenho preditivo e de critérios operacionais de compra e venda de contratos em datas próximas do vencimento, utilizando o Índice Sharpe como parâmetro de comparação entre os mercados.

Com base nos resultados obtidos, pode-se concluir que, para o período analisado, o modelo com melhor desempenho simulado nos três mercados é o ARIMA que, em função de sua rápida adaptabilidade e estrutura parcimoniosa, produz as melhores previsões em termos agregados, com médias positivas nas simulações de compra e venda de contratos futuros das três commodities. Os Modelos Lineares Dinâmicos também apresentam desempenho satisfatório, com retornos financeiros positivos derivados de sinalizações corretas da tendência de mercado, em especial no contrato futuro de boi gordo.

Já os modelos de Redes Neurais Artificiais geram resultados financeiros positivos nos mercados de boi gordo e soja, captando com certa precisão as reversões de tendência nesses mercados. Entretanto, a média negativa dos retornos para o contrato de café limitam a sua aplicabilidade como ferramenta de auxílio à tomada de decisão de agentes que transacionam esta commodity, que se notabiliza pela alta volatilidade de preços no mercado físico.

Observoutse ainda que a construção e ajuste dos modelos envolve um trade-off em termos da adaptação do modelo estimado à série de dados e seu poder de previsão. Ademais, os modelos Redes Neurais requerem um elevado grau de subjetividade na interpretação das variáveis envolvidas no processo de modelagem. Por esta raz̃o, o potencial de utilização de cada um dos métodos está associado à facilidade ou dificuldade na compreensão e aplicação dos mecanismos que determinam sua estimação, por parte dos agentes tomadores de decisão.

Os resultados deste trabalho fornecem uma wva ferramenta de análise do mercado de commodites agropecuárias, que pode ser utilizada para a identificação de tendências de preço em negociações num horizonte de curto prazo. Assim, analistas de commodities, administradores de carteiras, analistas técnicos e agentes de mercado podem buscar, a partir da utilização da modelagem apresentada, a 
sinalização de possíveis tendências semanais de evolução das cotações no mercado físico visando não somente a negociação de contratos futuros, como também transações do mercado físico e transações com opções sobre futuros.

Esta aplicabilidade é reforçada pelos resultados obtidos neste estudo. É possível afirmar, com base no desempenho preditivo e operacional, que a aplicabilidade de modelos estatísticos de previsão apresenta maior potencial em mercados com baixa liquidez. Tal constatação deriva do desempenho destacado dos modelos analisados no mercado futuro de soja em grão, o qual tem baixo volume de negociação, se comparado com os demais contratos agropecuários analisados.

Deve-se ressaltar que os resultados obtidos nesta pesquisa fornecem um indicativo do potencial de aplicação dos modelos estudados em operações nos mercados futuros agropecuários, não devendo, contudo, ser interpretados como uma resposta final sobre a aplicabilidade dos mesmos. Isto porque o processo de construção dos modelos pode variar, de acordo com os objetivos ou critérios adotados pelo analista. O potencial ou a limitação do desempenho dos modelos está diretamente ligado à esta subjetividade.

Neste sentido, a verificação para um período mais amplo de estudo (de preferência dez anos), bem como a análise envolvendo um maior número de commodities é necessária de modo a fornecer um indicativo da aplicabilidade dos modelos para um maior número de agentes participantes do mercado futuro de commodites agropecuárias.

Além disso, a consideração de estratégias mais complexas, envolvendo análises do tipo cash and carry, spreads, arbitragens ou opções de futuros podem corroborar os resultados que foram obtidos, aproximando-se de operações usualmente levadas a termo no mercado. A combinação de previsões entre os modelos é outro campo de estudo que pode ser explorado, com aplicações aos mercados futuros agropecuários no Brasil.

Artigo recebido em 09.04.2003. Aprovado em 12.08.2003

\section{REFERÊNCIAS BIBLIOGRÁFICAS}

ABRAHAM, B.; LEDOLTER, J. Statistical Methods for Forecasting. New York, John Wiley \& Sons, 1983. $445 \mathrm{p}$.

BM\&F. Agropecuários: açúcar, algodão, boi gordo, café, milho e soja. Curso de Introdução aos Mercados Futuros Agropecuários. Viçosa, 1997. 81p.

BOX, G. E. P.; JENKINS, G. M. Time Series Analysis: Forecasting and Control. San Francisco, Holden Day, 1976.

CHATFIELD, C. Model Uncertainty, Data Mining and Statistical Inference. In.: Journal of the Royal Statistical Society, serie A, vol. 158, parte 3, p. 419-466, 1995.

CHATFIELD, C.. Model Uncertainty and Forecast Accuracy. in.: Journal of Forecasting, vol. 15, p.495-508, 1996.

CORRÊA, W.R. PORTUGAL, M.S. Previsão de séries de tempo na presença de mudança estrutural: redes neurais artificiais e modelos estruturais. in.: Economia Aplicada, vol. 2, n 3, p.487-514, 1998. 
FARAWAY, J., CHATFIELD, C. Time series forecasting with neural networks: a case study. London: UK, Research Report 95-06, University of Bath, 1995. 20p.

FERNANDES, L. G. L., PORTUGAL, M. S., NAVAUX, P. O. A. Previsão de séries de tempo: redes neurais artificiais e modelos estruturais. In: ENCONTRO BRASILEIRO DE ECONOMETRIA, 17, Salvador, 1995. Anais... Salvador: Soc. Bras. de Econometria, 1995. p.399-416.

FISCHER, S. Séries univariantes de tempo: metodologia de Box \& Jenkins. Porto Alegre, FEE, 1982 186 p. Dissertação (Mestrado em Economia) - Universidade Federal do Rio Grande do Sul, 1982.

FITZPATRICK, D. W. Neural Net Primer: A Brief Introduction to the use of Neural Networks Suitable for Futures Forecast. 04/03/1999 http://www.jurikres.com/down/nnprimer.txt.

GARCIA, P.; LEUTHOLD, R. M.; FORTENBERY, T. R.; SARASSORO, G. F. Pricing Efficiency in the Live Cattle Futures Market: Further Interpretation and Measurement. in.: American Journal of Agricultural Economics, p.162-169, Fevereiro, 1988.

GRANGER, C. W. J.; NEWBOLD, P. Forecasting Economic Time Series. London, Academic Press, 1986. 211p.

GRUDNITSKI, G.; OSBURN, L. Forecasting S\&P and Gold Futures Prices: An Application of Neural Networks, in.: The Journal of Futures Markets. Vol. 13, n 6, p.631-643, 1993.

HARRISON, P. J.; STEVENS, C. F. Bayesian Forecasting. in.: Journal of the Royal Statistical Society, series B, vol. 38, n 3, p.81-135, 1976.

HARVEY, A.C. Forecasting Structural Time Series Models and the Kalman Filter. Cambridge: Cambridge University Press, 1991. 685p.

HAUGEN, R.A. Modern Investment Theory. Upper Saddle River, Prentice Hall, 1987. 748p.

HULL, J. Introdução aos Mercados Futuros e de Opções. São Paulo, BM\&F/Cultura, $2^{\mathrm{a}}$ ed., 1996. 445 .

JUST, R.E.; RAUSSER, G.C. Commodity Price Forecasting with Large-Scale Econometric Models and the Futures Markets, in.: American Journal of Agricultural Economics. n ${ }^{\circ}$ 63, p.197-208, 1981.

KENYON, D.; JONES, E.; McGUIRK, A. Forecasting Performance of Corn and Soybean Harvest Futures Contracts. in.: American Journal of Agricultural Economics, vol. 75, p. 399-407, Maio 1993.

KOHZADI, N., BOYD, M. S., KAASTRA, I., KERMANSHAHI, B. S., SCUSE, D. Neural networks for forecasting: an introduction. Canadian Journal of Agricultural Economics, n.43, 1995.

LEUTHOLD, R. M. The Price Performance of the Futures Market of a Nonstorable Commodity: Live Beef Cattle. in.: American Journal of Agricultural Economics, vol. 56, n², p. 64-78, 1974.

LEUTHOLD, R. M.; HARTMAN, P. A. A Semi-Strong Form Evaluation of the Efficiency of the Hog Futures Market. in.: American Journal of Agricultural Economics, vol. 61, n³, p. 482-489, 1979.

MAKRIDAKIS, S.; ANDERSEN, A.; CARBONE, R.; FILDES, R.; HIBON, M.; LEWANDOWSKI, 
R.; NEWTON, J.; PARZEN, E.; WINKLER, R. The Accuracy of Extrapolation (Time Series) Methods: Results of a Forecasting Competition. in.: Journal of Forecasting, vol.1, p. 111-153, 1982.

NTUNGO, C.; BOYD, M. Commodity Futures Trading Performance Using Neural Network Models versus ARIMA Models. in.: Journal of Futures Markets, vol. 18, nº, p.965-983, 1998.

POLE, A., WEST, M., HARRISON, I Applied bayesian forecasting and time series analysis. New York: Chapman \& Hall, 1994. 409p. (Texts in Statistical Science).

PORTUGAL, M. S. Neural networks versus time series methods: a forecasting exercise. Revista Brasileira de Economia, v.4, p.611-629, 1995.

PORTUGAL, M. S., FERNANDES, L. G. L. Redes neurais artificiais e previsão de séries econômicas: uma introdução. Nova Economia, v.6, n.1, p.51-73, 1996.

PINDYCK, R. S.; RUBENFIELD, D. L. Econometric Models and Economic Forecasts. New York, McGrawHill, 3rd Ed., 1991. 565p.

SCHWAGER, J. D. A Complete Guide to The Futures Markets: Fundamental Analysis, Technical Analysis, Trading, Spreads and Options. New York, Wiley, 1984. 540p.

SILVA, N. P. L. O Melhor Momento Para Comprar e Vender, sem trocar o pé (Whipsaw), in.: Resenha $B M \& F$, n$^{\circ} 113$, p. 53-61, out./nov. 1996.

SOUZA, R. C. Modelos Estruturais para Previsão de Séries Temporais: Abordagens Clássica e Bayesiana. Rio de Janeiro, IMPA, 1989. 171p.

TAYLOR, S. J. How Efficient Are The Most Liquid Futures Contracts? A Study of Treasury Bond Futures. in.: Review of Futures Markets, vol. 7 (suppl.), p. 574-592, 1988.

TOMEK, W.G. Commodity Futures Prices as Forecasts. in.: Review of Agricultural Economics, vol. 19, n 1, p. 44-68, 1997.

TURBAN, E. Decision Support and Expert Systems: Management Support Systems. New York, MacMillan, 1993. 832p.

VERE, D.T.; GRIFFITH, G. R. Comparative Forecast Accuracy in the New South Wales Prime Lamb Market. in.: Australian Journal of Agricultural Economics, vol. 34, n², p.103-117, 1990.

VICENTE, J. R. Modelos Estruturais para Previsão das Produções Brasileiras de Carne de Frango e Ovos. in.: Revista de Economia e Sociologia Rural. Brasília, vol. 30, n4, p.305-319, out./dez/ 1992.

\section{Aureliano Angel Bressan}

Professor Adjunto da CEPEAD-UFMG. Doutor em Economia Aplicada.

E-mail: bressan@ face.ufmg.br

Endereço: Rua Curitiba, no - 832/1009, Centro, Belo Horizonte - MG, CEP 30170-120

Interesses de Pesquisa: Futuros Agropecuários, Econometria Aplicada, Mercado de Capitais. 